\title{
Neck circumference as marker of overweight and obesity among secondary adolescents aged 12-19 years in southwestern Uganda: a cross-sectional survey
}

Godfrey Katamba ( $\sim$ cgmkats13@gmail.com )

King Ceasor University https://orcid.org/0000-0002-7456-0786

David Collins Agaba

Mbarara University of Science and Technology

Francis Muzaale

Gulu University Faculty of Medicine

Agnes Namaganda

Busitema University - Namasagali Campus

Rosemary Namayanja

Mbarara University of Science and Technology Faculty of Medicine

Abdul Musasizi

King Ceasor University

Mivule Abdul Kinene

King Ceasor University

Richard Migisha

Mbarara University of Science and Technology Faculty of Medicine

\section{Research}

Keywords: Overweight, Obesity, neck circumference, body mass index, Adolescents

Posted Date: February 18th, 2021

DOI: https://doi.org/10.21203/rs.3.rs-204357/v1

License: (9) This work is licensed under a Creative Commons Attribution 4.0 International License. Read Full License 


\section{Abstract \\ Background}

Overweight and obesity have become more common among adolescents. Various indicators have been used to assess this burden across populations. Recent findings elsewhere have found neck circumference to be useful in defining overweight and obesity. However, the use of neck circumference as marker of overweight and obesity needs to be further explored among adolescents in Uganda.

\section{Objective}

To assess the usefulness of neck circumference as a marker of overweight and obesity.

\section{Methods}

A cross sectional study was conducted among secondary adolescents aged 12-19 years from May to August in 2018, Height was measured using a wall mount height board and weight using a standard weighing scale. Neck circumference was measured using an inelastic measuring tape. We defined overweight as $\mathrm{BMI}=25.0-29.9 \mathrm{~kg} / \mathrm{m}^{2}$ while obesity as $\mathrm{BMI} \geq 30.0 \mathrm{~kg} / \mathrm{m}^{2}$ among the study participants. Pearson correlation coefficient was used to determine the correlation between neck circumference, height, weight and body mass index. Receiver operating characteristic (ROC) curve analysis was used to determine the suitable cutoff of neck circumference for overweight and obesity.

\section{Results}

We enrolled 616 adolescents aged $12-19$ years, with mean age of $15.6 \pm 2.0$ years. Most $(65.6 \%)$ were female. The overall prevalence of overweight was $30.5 \%$ while that of obesity was $3.4 \%$. Neck circumference was significantly correlated with height $(r=0.561, P<0.001)$, weight $(r=0.547, P<0.001)$ and body mass index $(r=0.193, P<0.001)$. The best cutoff of neck circumference to identify participants with obesity were $\geq 31.0 \mathrm{~cm}$ with AUC of $0.83[0.73-0.94]$ and $\geq 32.0 \mathrm{~cm}$ with an AUC of $0.59[0.11-1.00]$ among the females and males respectively.

\section{Conclusion}

Neck circumference was useful in defining and hence classifying for overweight or obesity among the female adolescents in our study population. It could useful for screening for overweight and obesity among the female adolescents.

\section{Introduction}


Overweight and obesity, according to the world health organization (WHO), are defined as excessive accumulation of fat that may impair health. Obesity and overweight are a global problem, and in 2016 alone, according to WHO, over 340 million children and adolescents aged 5-19 years were overweight or obese. The burden of obesity and overweight is highly linked to the incidence of non-communicable diseases ranging from diabetes mellitus, cardiovascular disease (CVD) [1] among others. Several anthropometric indices have been proposed to ease the identification of overweight or obesity. Among these, body mass index (BMI) is the most commonly used anthropometric index [2]. Several others such as waist circumference (WC), waist hip ratio (WHR), neck circumference (NC) and waist height ratio (WHtR) have also been proposed [3-5]. Neck circumference, has of recent attracted attention in health research and clinical settings. It has been reported to have potential of accurately define overweight and obesity across several populations [6-12], yet it is easy to measure. A cross-sectional study conducted in Indonesia that involved up to 1554 participants found high prevalence $(79.7 \%)$ of obesity. In the same study, NC was found to be significantly correlated with BMI and WC, and was found to be useful for screening for overweight and obesity [7]. The study proposed cutoffs of $33.5 \mathrm{~cm}$ among the females and $37 \mathrm{~cm}$ among the males with high value of specificity and sensitivity. Among Bangladesh adults, NC was found to have the ability to distinguish overweight and obese adults from their counterparts [10]. Findings from a study that included 864 children and adolescents from Iran, showed that NC was significantly correlated with BMI, WC and Mid upper arm circumference (MUAC) [13]. The proposed NC cutoffs for overweight or obesity were $27.5-38.3 \mathrm{~cm}$ in boys versus $26.7-33.4 \mathrm{~cm}$ in girls. All the findings give highly credible data on the usefulness of NC in screening for overweight or obesity. However, other studies are needed to localize finding to Uganda's population with emphasis on adolescents, with overweight and obesity currently affecting $12 \%$ of the Ugandan adolescents and young adults of 12-24 years [14]. We aimed to assess the usefulness of neck circumference as a marker of overweight or obesity.

\section{Methods}

This was a cross-sectional study conducted among secondary school adolescents in Mbarara Municipality, southwestern Uganda from May to August 2018.

\section{Data collection}

Age and sex of the participants was self-reported in complete years. Neck circumference (NC) was assessed as a surrogate measure for upper body adipose tissue distribution. It was measured at the level of the laryngeal prominence using an inelastic flexible measuring tape, with the subjects in the standing position, and the head held erect and eyes facing forward to the nearest $0.1 \mathrm{~cm}[9,15]$.

Height was measured in centimeters with the participant shoeless and rear body parts touching the board while the head is facing forward, using a wall mount height board without shoes [15-17].

Weight was measured to the nearest $0.5 \mathrm{~kg}$ using a standard weighing scale (Seca 762, GmbH \& Co. KG, Hamburg, Germany). The participants were encouraged to put on light clothes and without items in the pocket $[15,18]$. The participants were not allowed to put on shoes. 
Body mass index (BMI) was calculated as the ratio of the weight of the participant in kilograms to height in square meters [19]. Overweight was defined as BMI $=25.0-29.9 \mathrm{~kg} / \mathrm{m}^{2}$ while obesity as BMI $\geq 30.0 \mathrm{~kg} / \mathrm{m}^{2}$.

\section{Statistical analysis}

Data were collected in excel form powered by open data kit, and were analyzed using Stata 13.0 (College Station, Texas, USA). All data were analyzed and reported according sex category. The means and standard deviations (SD) were used to describe continuous variables while for the categorical data, frequencies and percentages were estimated. The associations between NC and other anthropometric variables of the studied participants were assessed using Pearson's correlation analysis. Receiver operating characteristic (ROC) curve analysis was used to determine optimal sex-specific cutoffs of NC in relation to BMI. The cutoff was considered as the value of NC that showed the maximum Youden's $\mathrm{J}$ statistic[20]. Area under the curve (AUC) and its $95 \%$ confidence interval were reported. Statistical significance was set at $p<0.05$.

\section{Results}

\section{Characteristics of study population}

The baseline characteristics of study participants have been described in detail elsewhere [15]. Briefly, data of 616 adolescents, of which 212 were males was analyzed. The mean age of the participants was $15.6 \pm 2.0$ years, mean height of $1.6 \pm 0.08$ meters, weight of $59.5 \pm 8.4 \mathrm{~kg}$ and lastly a mean BMl of $23.9 \pm 3.0 \mathrm{~kg} / \mathrm{m}^{2}$.

\section{Distribution of BMI categories among study participants}

Among our study participants, the prevalence of obesity was higher among the females at $4.5 \%(n=18)$ in comparison to $1.4 \%(n=3)$ among the males. The overall prevalence of obesity was $3.4 \%$. as shown in table 1.

\section{Correlation of neck circumference with other obesity indicators}

Overall, there was a significant $(\mathrm{p}<0.001)$ positive Pearson correlation coefficient between $\mathrm{NC}$ and height $(\mathrm{r}=0.56, P<0.001)$; weight $(\mathrm{r}=0.55, \mathrm{P}<0.001)$; and BMI $(\mathrm{r}=0.19, P<0.001)$, as shown in Table 2. After stratifying for sex, all correlations were positive and significant among the females. Among the males, the correlation between NC and BMI was positive but not significant.

\section{Receiver operating characteristic (ROC) curve analysis}

Among the males, a cut off of NC $\geq 29.8 \mathrm{~cm}$ was optimal for defining overweight with an AUC of 0.60[0.54-0.66] as shown in Figure 1. In Figure 2, the cutoff of obesity among the males was determined as NC $\geq 32.0 \mathrm{~cm}$ with a recorded AUC of 0.59 [0.11-1.00]; however, this was low and had a wide 
confidence interval overlapping with the null as shown in Table 3. Among the females, a cutoff of $\mathrm{NC} \geq$ $29.8 \mathrm{~cm}$ was appropriate to indicate overweight with a recorded AUC of 0.5993 as shown in figure 3 , while $\mathrm{NC} \geq 31.0 \mathrm{~cm}$ indicated obesity with a very high AUC of $0.83[0.73-0.94]$, with of positive predictive values and negative predictive values of 0.778 and 0.741 respectively.

\section{Discussion}

The findings from our study, revealed the usefulness of measuring NC to screen for overweight and obesity among adolescents in Uganda. A positive correlation between NC and BMI was generally reported. We also determined the reliable cutoff values for overweight and obesity in both sexes, with NC being more useful and accurate among the girls in defining overweight and obesity. This could be attributed to the fact that AUC depends greatly on the prevalence of the disease, given that obesity was more among the females (4.5\%) than the males (1.4\%) in our study population. Additionally, our study findings have given a green light to large nationwide surveys to assess the usefulness of NC in defining overweight or obesity. Our findings are in agreement with several studies that reported positive significant correlations between NC, and other indicators of overweight or obesity. Among 1102 children and adolescents, a positive correlation was reported between NC, BMI and WC among others [21]. The same study proposed NC cutoffs among boys ranging from 28 to $39.0 \mathrm{~cm}$, while among the girls, the cutoffs ranged from 27.0 to $34.6 \mathrm{~cm}$. Furthermore, the same and related findings were reported among 412 adolescents aged 6-18 years that were recruited from the Endocrinology department of Erciyes University in Turkey[22]. The same findings were reported in Egypt, by a study that involved overweight and obese adults [23]. The other studies reporting the same related findings include [7, 24]. Our study, was the first of a kind to report such results from adolescents in Uganda. Based on our findings, we recommend that an extensive and highly inclusive study be conducted to determine the overall cutoffs and further exploitation of the relationship of NC with metabolic syndrome and its components such as hyperlipidemia, diabetes and hypertension. However, despite of the results, there are several limitations to our findings. The study was considered only in southwestern Uganda and only among secondary school adolescents in Mbarara municipality, which is more urbanized municipality. This makes results generalization less likely. Additionally, our analysis was based on the AUC from ROC analysis and this is generally affected by the prevalence of the disease among the study population. Thus, the results here may not apply to areas with very high prevalence of overweight or obesity.

\section{Conclusion}

Neck circumference is an easy and noninvasive marker of obesity among the females in our study population compared to males. It can be used for screening for obesity among only the female adolescents.

\section{List Of Abbreviations}

AUC 
Area under the curve

BMI

Body mass index

$\mathrm{Cl}$

Confidence interval

MUAC

Mid upper arm circumference

NC

Neck circumference

NPV

Negative predictive value

PPV

Positive predictive value

ROC

Receiver operating characteristic

WC

waist circumference

WHO

World health organization

WHR

Waist hip ratio

WHtR

Waist height ratio

\section{Declarations}

\section{Ethics approval and consent to participate}

Ethical approval was obtained from Mbarara University of Science and Technology research ethics committee (IRB number: 18/03-18). Those aged 18-19 years consented for themselves, while the adolescents aged 12-17 years assented and the school administration and class their teachers consented on their behalf.

\section{Consent for publication}

Not applicable

\section{Availability of data and materials}

Data and materials ware available on request from the corresponding author.

\section{Competing interests}


The authors declare no competing interests.

\section{Funding}

The study received no external funding.

\section{Authors' contributions}

GK, DCA and RM: Conceptualization of work \& its realization, wrote the manuscript, checked the references, compiled the literature sources, data collection, statistical analysis, and interpretation of data, and wrote the manuscript. FM, HM and RN: mentored the conceptualization of work \& its realization, compiling literature sources and statistical analysis, helped in data interpretation, guided manuscript writing, checked the references. AM, KAM and AN: helped in the conceptualization of the work, helped in statistical and data analysis, support to data collection. All authors read and approved the manuscript before submission.

\section{Acknowledgements}

The study participants are highly appreciated.

\section{References}

1. Must A, Spadano J, Coakley EH, Field AE, Colditz G, Dietz WHJJ. The disease burden associated with overweight and obesity. JAMA. 1999;282(16):1523-9.. 10.1001/jama.282.16.1523.

2. Lim JU, Lee JH, Kim JS, Hwang YI, Kim T-H, Lim SY, Yoo KH, Jung K-S, Kim YK, Rhee CK. Comparison of World Health Organization and Asia-Pacific body mass index classifications in COPD patients. Int J Chron Obstruct Pulmon Dis. 2017;12:2465-75. 10.2147/COPD.S141295.

3. Ben-Noun L, Sohar E, Laor A. Neck circumference as a simple screening measure for identifying overweight and obese patients. Obes Res. 2001;9(8):470-7. 10.1038/oby.2001.61.

4. Patnaik L, Pattnaik S, Rao EV, Sahu T. Validating neck circumference and waist circumference as anthropometric measures of overweight/obesity in adolescents. Indian Pediatr. 2017;54(5):377-80. 10.1007/s13312-017-1110-6.

5. Folmann AG, Wolf VLW, Roman EP, Guerra-Júnior G. Neck circumference and excess weight: proposal of cutoff points for Brazilian adolescents. Jornal de Pediatria 2020:https://doi.org/10.1016/j.jped.2020.02.005.

6. Alfadhli EM, Sandokji AA, Zahid BN, Makkawi MA, Alshenaifi RF, Thani TS, Habeeb HA. Neck circumference as a marker of obesity and a predictor of cardiometabolic risk among Saudi subjects. Saudi Med J. 2017;38(12):1219-23. 10.15537/smj.2017.12.20926.

7. Lindarto D, Shierly, Syafril S. Neck Circumference in Overweight/Obese Subjects who Visited the Binjai Supermall in Indonesia. Open Access Maced J Med Sci. 2016;4(3):319-23.

10.3889/oamjms.2016.072. 
8. Ma C, Wang R, Liu Y, Lu Q, Liu X, Yin F. Diagnostic performance of neck circumference to identify overweight and obesity as defined by body mass index in children and adolescents: systematic review and meta-analysis. Annals of human biology. 2017;44(3):223-9.

10.1080/03014460.2016.1224387.

9. Pei X, Liu L, Imam MU, Lu M, Chen Y, Sun P, Guo Y, Xu Y, Ping Z, Fu X: Neck circumference may be a valuable tool for screening individuals with obesity: findings from a young Chinese population and a meta-analysis. BMC public health 2018, 18(1):529:10.1186/s12889-018-5448-z.

10. Qureshi NK, Hossain T, Hassan MI, Akter N, Rahman MM, Sultana MM, Ashrafuzzaman SM, Latif ZA. Neck Circumference as a Marker of Overweight and Obesity and Cutoff Values for Bangladeshi Adults. Indian journal of endocrinology metabolism. 2017;21(6):803-8. 10.4103/ijem.IJEM_196_17.

11. Yang G-R, Dye TD, Zand MS, Fogg TT, Yuan S-Y, Yang J-K, Li D: Association Between Neck Circumference and Coronary Heart Disease: A Meta-analysis. Asian Pac Is/ Nurs J 2019, 4(1):3446:10.31372/20190401.1031.

12. Zaciragic A, Elezovic M, Avdagic N, Babic N, Dervisevic A, Lepara O, Huskic J. Relationship between the Neck Circumference, Standard Anthropometric Measures, and Blood Pressure in Bosnian Young Adults. Eurasian J Med. 2019;51(2):150-3. 10.5152/eurasianjmed.2018.18197.

13. Taheri M, Kajbaf TZ, Taheri M-R, Aminzadeh MJOMJ. Neck circumference as a useful marker for screening overweight and obesity in children and adolescents. Oman Med J. 2016;31(3):170. 10.5001/omj.2016.34.

14. Nsanya MK, Kavishe BB, Katende D, Mosha N, Hansen C, Nsubuga RN, Munderi P, Grosskurth H, Kapiga SJTJoCH. Prevalence of high blood pressure and associated factors among adolescents and young people in Tanzania and Uganda. J Clin Hypertens (Greenwich). 2019;21(4):470-8. 10.1111/jch.13502.

15. Katamba G, Agaba DC, Migisha R, Namaganda A, Namayanja R, Turyakira EJIJoP. Prevalence of hypertension in relation to anthropometric indices among secondary adolescents in Mbarara, Southwestern Uganda. Ital J Pediatr. 2020;46(1):1-7:. https://doi.org/10.1186/s13052-020-00841-4.

16. Gardasevic JJSM. Relationship between sitting height measurements and standing height: a prospective regional study among adolescents in eastern region of Kosovo. Int $\mathrm{J}$ Morphol. 2018;16(2):15-9:. http://dx.doi.org/10.4067/S0717-95022020000601681.

17. Katamba G, Agaba DC, Migisha R, Namaganda A, Namayanja R, Turyakira EJJoHH. Using blood pressure height index to define hypertension among secondary school adolescents in southwestern Uganda. J Hum Hypertens. 2020;34(1):76-81. 10.1038/s41371-019-0292-x.

18. Ali Z, Abizari A-RJNj. Ramadan fasting alters food patterns, dietary diversity and body weight among Ghanaian adolescents. Nutr J. 2018;17(1):75.. https://doi.org/10.1186/s12937-018-0386-2.

19. Agaba DC, Migisha R, Namayanja R, Katamba G, Lugobe HM, Aheisibwe H, Twesigomwe G, Ashaba SJBRI. Prevalence and Associated Factors of Metabolic Syndrome among Patients with Severe Mental IIIness Attending a Tertiary Hospital in Southwest Uganda. Biomed Res Int 2019, 2019:10.1155/2019/1096201. 
20. Youden WJ: Index for rating diagnostic tests. Cancer 1950, 3(1):32-35:10.1002/1097 0142(1950)3:1 < 32::aid-cncr2820030106 > 3.0.co;2-3.

21. Nafiu OO, Burke C, Lee J, Voepel-Lewis T, Malviya S, Tremper KK. Neck circumference as a screening measure for identifying children with high body mass index. Pediatrics 2010, 126(2):e30610:10.1542/peds.2010 - 0242.

22. Hatipoglu N, Mazicioglu MM, Kurtoglu S, Kendirci M. Neck circumference: an additional tool of screening overweight and obesity in childhood. Eur J Pediatrics. 2010;169(6):733-9. 10.1007/s00431-009-1104-z.

23. El Din AS, Hassan N, El-Masry S, Al-Tohamy MJMJoMS. Neck circumference as a simple screening measure for identifying Egyptian overweight and obese adults. Macedonian Journal of Medical Sciences. 2013;6(3):232-7.. https://doi.org/10.3889/mjms.1857-5773.2013.0309.

24. Ben-Noun L, Sohar E, Laor A: Neck circumference as a simple screening measure for identifying overweight and obese patients. Obesity Research. 2001; 9 (8): 470-7. Obes Res 2001:10.1038/oby.2001.61.

\section{Tables}

Table 1: Distribution of BMI categories among study participants

\begin{tabular}{llll}
\hline BMI category & Male $(\mathrm{n}=212)$ & Female $(\mathrm{n}=404)$ & Total $(\mathrm{n}=616)$ \\
\hline Underweight & $15(7.1)$ & $5(1.2 \%)$ & $20(3.3 \%)$ \\
Normal weight & $172(81.1)$ & $215(53.2 \%)$ & $387(62.8 \%)$ \\
Overweight & $22(10.4)$ & $166(41.1 \%)$ & $188(30.5 \%)$ \\
Obesity & $3(1.4)$ & $18(4.5 \%)$ & $21(3.4 \%)$ \\
\hline
\end{tabular}

Table 2: Pearson correlation coefficient between neck circumference and other obesity variables

\begin{tabular}{lllllll}
\hline Variable & \multicolumn{7}{c}{ NC (cm) } \\
\cline { 2 - 7 } & \multicolumn{7}{c}{ Male $(\mathrm{n}=212)$} & Female $(\mathrm{n}=404)$ & \multicolumn{2}{c}{ Total $(\mathrm{n}=616)$} \\
\cline { 2 - 7 } & $\mathrm{r}$ & $\mathrm{p}$ & $\mathrm{r}$ & $\mathrm{p}$ & $\mathrm{r}$ & $\mathrm{p}$ \\
\hline Height (m) & 0.59 & $<0.01$ & 0.55 & $<0.01$ & 0.56 & $<0.01$ \\
Weight $(\mathrm{kg})$ & 0.53 & $<0.01$ & 0.70 & $<0.01$ & 0.55 & $<0.01$ \\
BMI $\left(\mathrm{kg} / \mathrm{m}^{2}\right)$ & 0.09 & 0.21 & 0.40 & $<0.01$ & 0.19 & $<0.01$ \\
\hline
\end{tabular}

$\mathrm{BMI}=$ Body mass index, $\mathrm{NC}=$ neck circumference

Table 3: Showing the proposed threshold for neck circumference in defining overweight or obesity by sex 


\begin{tabular}{lllllll}
\hline Sex & Cutoff $(\mathrm{cm})$ & Se & Sp & PPV & NPV & AUC [95\%CI] \\
\hline Males & & & & & & \\
Overweight & $\geq 29.8$ & 0.185 & 0.990 & 0.667 & 0.493 & $0.60[0.48-0.72]$ \\
Obesity & $\geq 32.0$ & 0.035 & 0.994 & 0.667 & 0.732 & $0.59[0.11-1.00]$ \\
Females & & & & & & \\
Overweight & $\geq 29.8$ & 0.736 & 0.994 & 0.944 & 0.446 & $0.60[0.54-0.66]$ \\
Obesity & $\geq 31.0$ & 0.123 & 0.986 & 0.778 & 0.741 & $0.83[0.73-0.94]$ \\
\hline
\end{tabular}

PPV; positive predictive value, NPV; negative predictive value, Se; sensitivity, Sp; specificity, AUC; area under the curve, CI; confidence interval

\section{Figures}

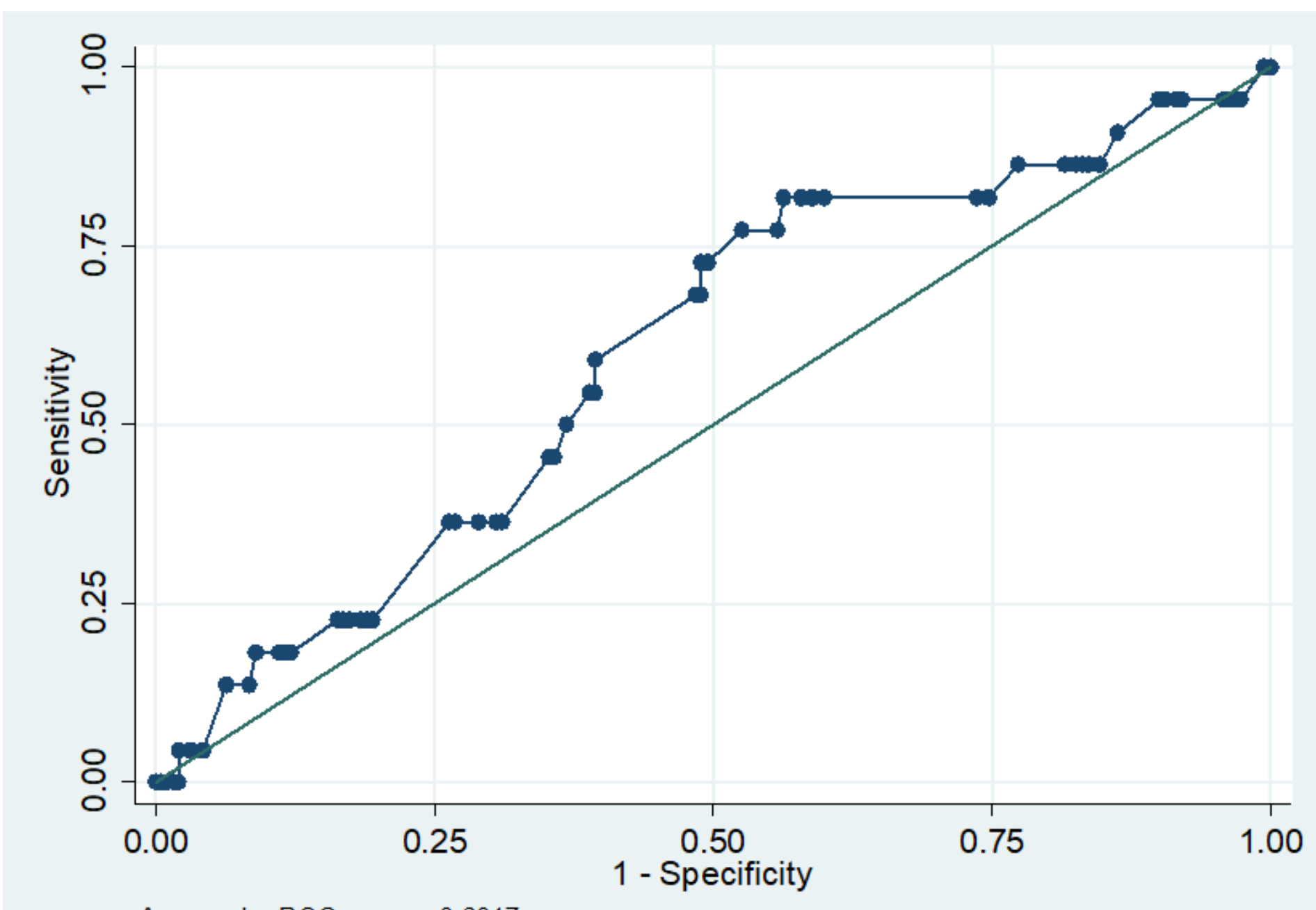

Area under ROC curve $=0.6017$

\section{Figure 1}

Receiver operating curve analysis of neck circumference with male overweight participants (BMI $=25.0-$ $29.9 \mathrm{~kg} / \mathrm{m} 2$ ). NC cut off $\geq 29.8 \mathrm{~cm}$ 


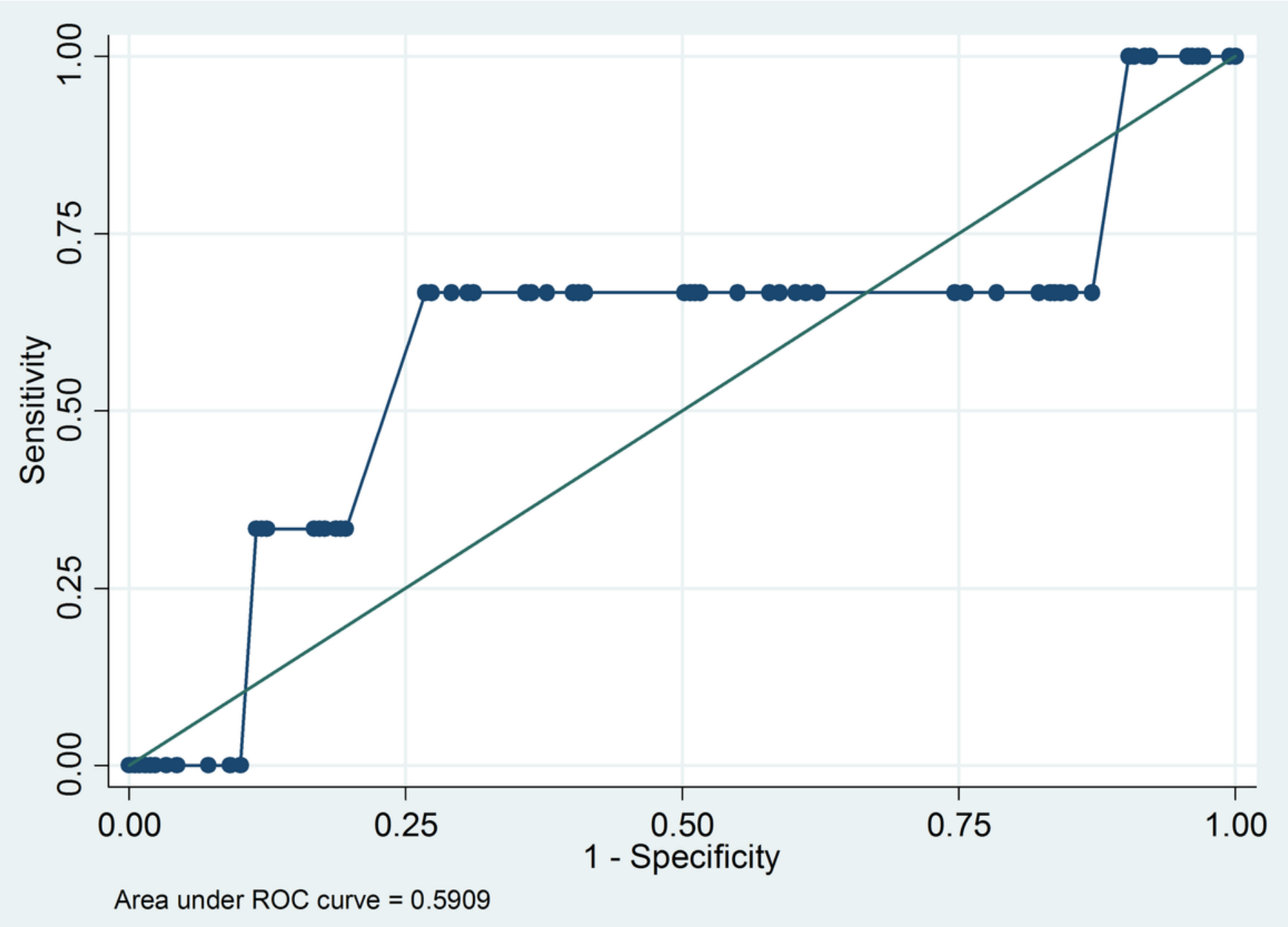

Figure 2

Receiver operating curve analysis of neck circumference with male obese participants (BMI $\geq 30.0 \mathrm{~kg} / \mathrm{m} 2$ ). $\mathrm{NC}$ cut off $\geq 32.0$ 


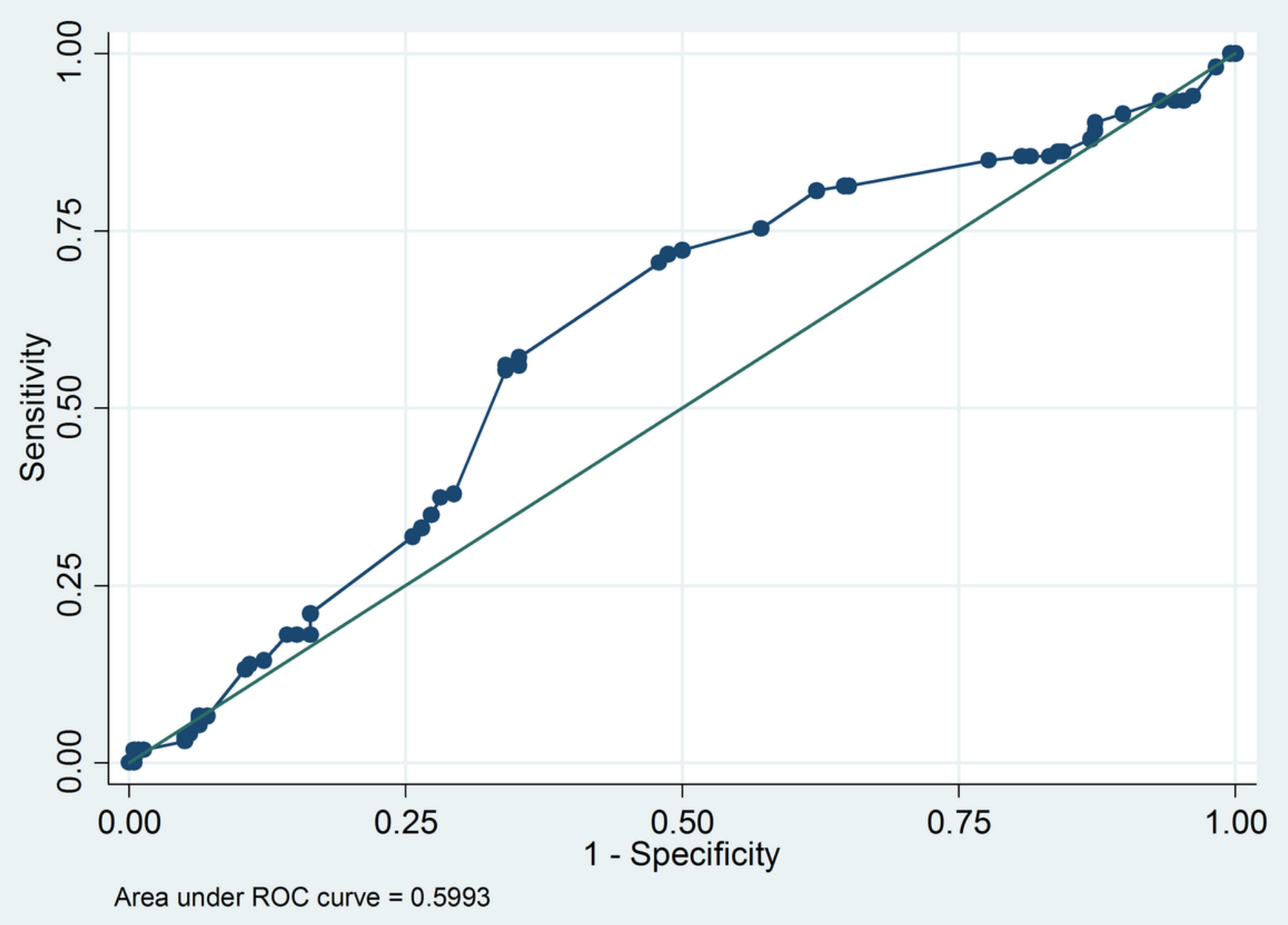

Figure 3

Receiver operating curve analysis of neck circumference with female overweight participants $(\mathrm{BMI}=25.0$ $29.9 \mathrm{~kg} / \mathrm{m} 2$ ). NC cut off $\geq 29.8 \mathrm{~cm}$ 


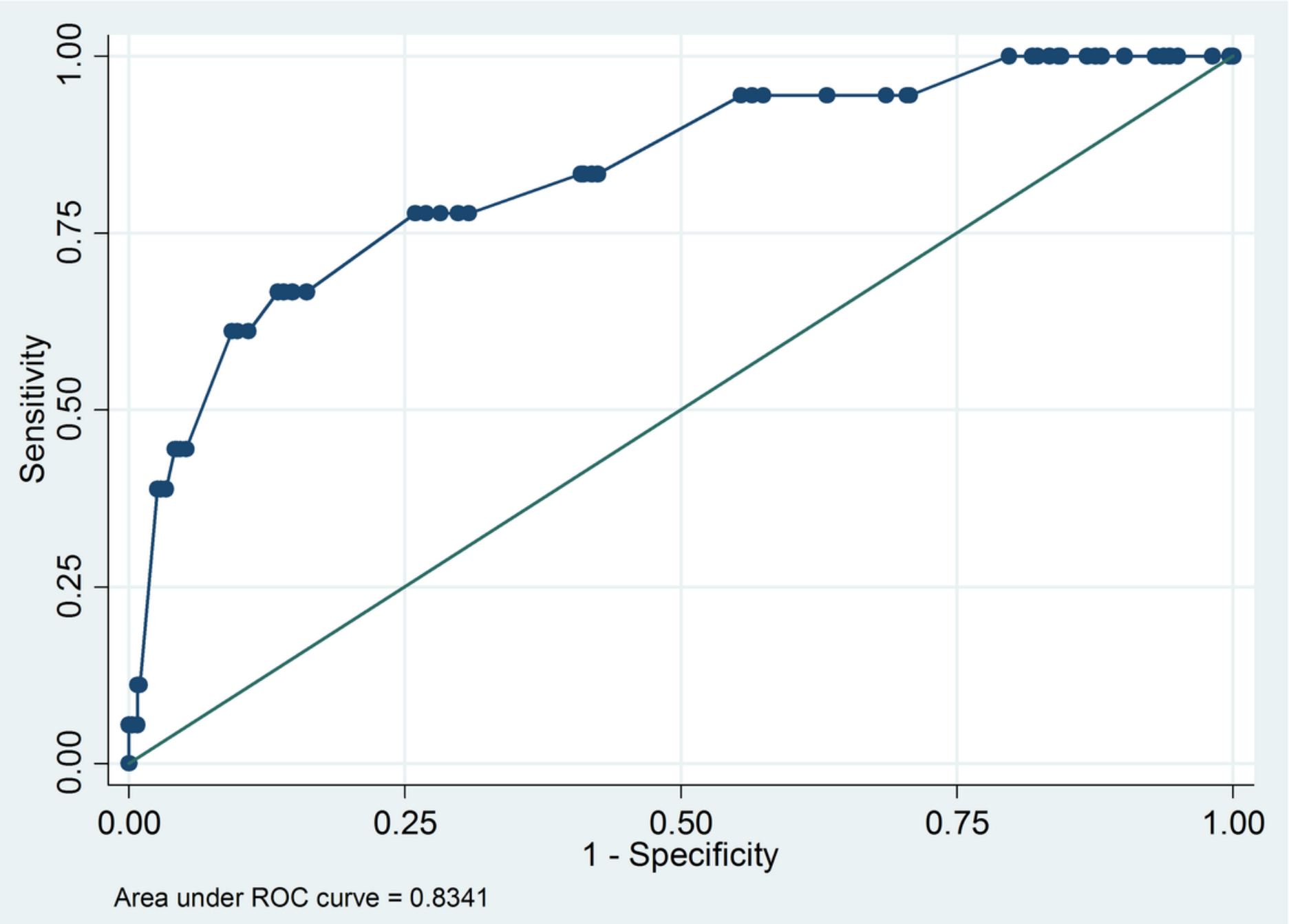

Figure 4

Receiver operating curve analysis of neck circumference with female obese participants (BMI $\geq 30.0 \mathrm{~kg} / \mathrm{m} 2$ ). $\mathrm{NC}$ cut off $\geq 31.0 \mathrm{~cm}$ 